Original Research Paper

\title{
Heat Transfer and Effectiveness Analysis of a Cross-Flow Heat Exchanger for Potential Energy Recovery Applications in Hot-Humid Climate
}

\author{
${ }^{1}$ Masitah, A.R.S., ${ }^{1}$ Mardiana I Ahmad and ${ }^{2}$ Y.M. Yatim \\ ${ }^{1}$ Energy, Indoor \& Environmental Quality Research Group, School of Industrial Technology, \\ Universiti Sains Malaysia, 11800 Pulau Pinang, Malaysia \\ ${ }^{2}$ School of Mathematical Sciences, Universiti Sains Malaysia, 11800 Pulau Pinang, Malaysia
}

\author{
Article history \\ Received: 09-12-2014 \\ Revised: 02-01-2015 \\ Accepted: 29-04-2015 \\ Corresponding Author: \\ Mardiana I Ahmad \\ Energy, Indoor and \\ Environmental Quality \\ Research Group, School of \\ Industrial Technology, \\ Universiti Sains Malaysia, \\ 11800 Pulau Pinang, Malaysia \\ Email:drmia707@gmail.com
}

\begin{abstract}
This paper presents heat transfer and effectiveness analysis based on a physical model of a cross-flow heat exchanger. Using the model, the transferred heat and effectiveness $(\varepsilon)$ in terms of temperature and NTU-method are calculated for both hot and cold streams. From the analyses, it is found that as air velocity increases, the transferred heat through heat transfer plates increases. In contrary, when air velocity decreases, the effectiveness increases. Further, as the air temperature of hot exhaust stream increases, both the transferred heat and effectiveness decrease. The study suggests that the calculated results provide benchmark data to evaluate and predict the performance of heat exchanger for energy recovery application.
\end{abstract}

Keywords: Heat Exchanger, Heat Transfer, Effectiveness, NTU, Energy Recovery

\section{Introduction}

The utilisation of energy recovery devices has been approved as one of energy-efficient technologies that could save a large fraction of thermal load since heat or energy would be transferred from the warmer airstream. As reported in Mardiana-Idayu and Riffat (2012), energy recovery system poses particular physical components, which makes it unique in its operation and behaviour as well affects its performance. Energy recovery system comprises of ductworks for inlets and outlets, fans and a core which is a heat exchanger (Min and Su, 2010). Heat exchangers are devices that provide the transfer of thermal energy between two or more fluid streams at different temperatures. According to Shah and Sekulic (2003), heat exchangers can be classified into several classifications as follows: (i) Recuperators or regenerators; (ii) type of construction (tubes, plates and extended surfaces); (iii) transfer process (direct contact or indirect contact); (iv) flow arrangement (parallel flow, counter flow or cross flow) and; (iv) heat transfer mechanism (single phase and two phase). Heat exchangers can also be categorised into several classifications based on construction type such as fixed-plate and heat pipe (Lin et al., 2005).
A lot of studies have been carried out in relation to heat exchangers for energy recovery applications since 1980s (Shurcliff, 1988; Sauer and Howell, 1981) either theoretically of experimentally (Yau, 2001; Nasif et al., 2010; Hviid and Svendsen, 2011). These also included efforts on the heat transfer and effectiveness analysis of various heat exchanger types (Pongsoi et al., 2012; Xie et al., 2009; Soylemez, 2000). For instance, Persily (1982) reported a work on a fixed-plate cross-flow heat exchanger based on experimental approach for building applications. On the other hand, Zhang and Jiang (1999) developed a numerical model and validated the data against the experimental results of a rectangular heat exchanger for building applications. Several studies also have been conducted on the heat exchangers for energy recovery system in cold climates (Alonso et al., 2014; Kragh et al., 2007). Although a great deal of works has been found, a gap still exists in the fundamental works of heat exchangers for energy recovery application in hot-humid climate zone. Thus, to close this gap this paper presents heat transfer and effectiveness analysis of a heat exchanger for potential energy recovery application in hot-humid climate. 


\section{Methodology}

\section{Physical Model}

The heart of an energy recovery system is heat exchanger which is the core or a matrix containing the heat transfer area (Mardiana-Idayu and Riffat, 2013). This heat transfer area is an area of the exchanger that is in direct contact with fluids and through which heat or energy is transferred. Figure 1 shows the cross-flow heat exchanger. The exchanger contains alternate corrugated plates arranged in a cross-flow manner. In this process, on one side of one stream exchanges heat that circulates to the other side of the wall and on another side of the wall, another stream is fresh air from outside exchanges heat from the opposite side of the wall, whereby outgoing and incoming streams can be prevented from mixing within the core. The corrugated structure supports two pieces of plate to divide each air tunnel into a large number of triangular channels; whereby such configuration allows air to change direction in a manner that ensures sufficient air comes in contact with the heat transfer surface prior to leaving the core.

\section{Heat Transfer}

Based on the physical model described in previous section, several assumptions are made as follows:

- Heat transfer process is at steady state

- The fluid is incompressible with constant physical properties

- Heat conduction in the two air streams is negligible compared in the two air streams and negligible compared to the energy transport by bulk flow

- Heat conductivity in the plates is constant

- The entrance and surface temperature are uniform

- Heat transfer in the airstreams is two dimensional (in $x$ and $y$ directions)

To design or to predict the performance of a heat exchanger, it is essential to relate the total heat transfer rate to quantities such as the inlet and outlet fluid temperatures, overall heat transfer coefficient and the total surface area for heat transfer. If $Q$ is the total rate of heat transfer (transferred heat) between hot and cold fluids and there is negligible heat transfer between the exchanger and its surroundings (assume no heat losses), as well as negligible potential and kinetic energy changers, application of the steady flow energy equation gives:

$Q=\dot{m}_{h}\left(i_{h i}-i_{h e}\right)$

And:

$Q=\dot{m}_{c}\left(i_{c i}-i_{c e}\right)$ where, $i$ is the fluid enthalpy and $\dot{m}$ is the mass airflow rate. The subscripts $h$ and $c$ refer to the hot and cold fluids, whereas the subscripts $i$ and $e$ designate the fluid intake and exhaust conditions, respectively.

These expressions reduce to:

$Q=\dot{m}_{h} c_{p, h}\left(T_{h i}-T_{h e}\right)$

And:

$Q=\dot{m}_{c} c_{p, c}\left(T_{c i}-T_{c \mathrm{e}}\right)$

where, $c_{p}$ is the heat capacity of air and $T$ is the temperatures appearing at the locations.

\section{Heat Transfer Coefficient}

The convective heat transfer coefficient, $h$ can be calculated from:

$h=\frac{N u \cdot k}{d}$

where, $N u$ is the Nusselt number and $d$ is the subchannel height.

The heat transfer coefficient is developed by using Nusselt number as follows:

$N u=0.332 \operatorname{Re}^{1 / 2} \operatorname{Pr}^{1 / 3}$

where, $R e$ is the Reynolds number and $\operatorname{Pr}$ is the Prandtl number and $l_{z}$ is length of airstream of the plates.

Reynolds number of a flow is calculated as:

$\operatorname{Re}=\frac{u \cdot d}{v}$

where, $u$ is the velocity of the fluid and $v$ is the kinematic viscosity $\left(\mathrm{m}^{2} / \mathrm{s}\right)$. This also can be interpreted as ratio of the inertia and viscous forces.

Prandtl number is calculated as:

$\operatorname{Pr}=\frac{v}{\alpha}$

where, $\alpha$ is the thermal diffusivity.

\section{Effectiveness of Heat Exchanger}

The concept of effectiveness is applied to the heat transfer process in a heat exchanger. The effectiveness of heat exchanger is defined as:

$$
\varepsilon=\frac{\text { actual heat transfer }}{\text { maximum possible heat transfer }}
$$




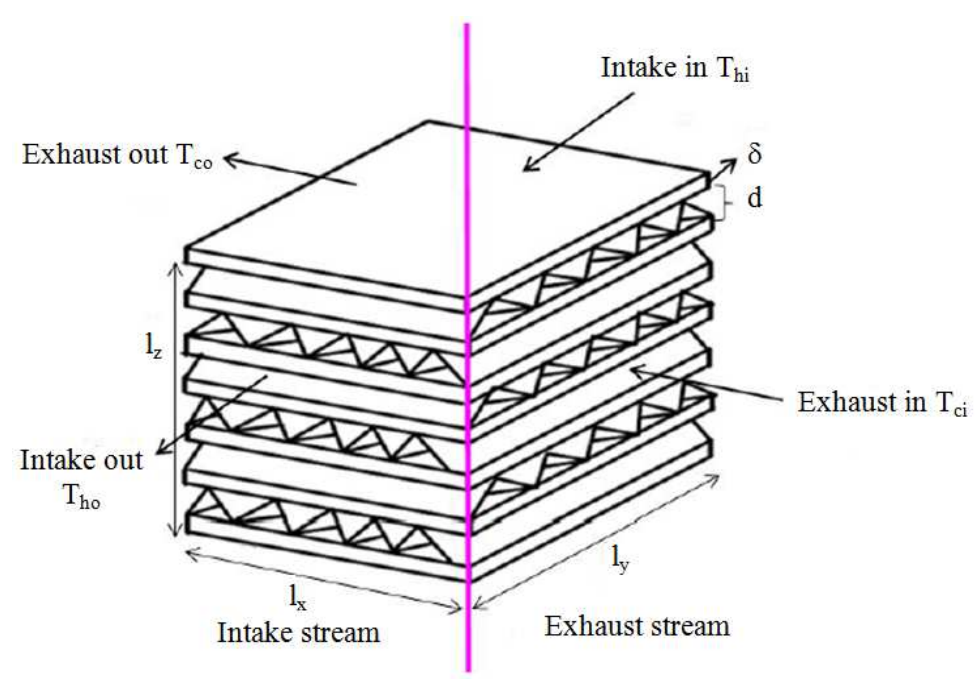

Fig. 1. Physical model of cross-flow heat exchanger

$\varepsilon=\frac{\dot{m}_{h} c_{p}\left(T_{h i}-T_{h e}\right)}{\dot{m}_{c} c_{p}\left(T_{h i}-T_{c i}\right)}$

A number of heat transfer unit is used to reflect the sensible heat transfer in heat exchanger. The number of heat transfer units for sensible heat is:

$N T U=\frac{U A}{\left(\dot{m} c_{p}\right)_{\text {min }}}$

$\frac{1}{U A}=\frac{1}{h_{h}}+\frac{\delta}{k \cdot A}+\frac{1}{h_{c} \cdot A}$

Where:

$U \quad=$ The overall heat transfer

$\mathrm{NTU}=$ The number of heat transfer unit

$A \quad=$ The contact area for each fluid side

$k \quad=$ The thermal conductivity

$h_{h} \quad=$ Convective heat transfer coefficient for hot stream

$h_{c}=$ Convective heat transfer coefficient for cold stream and

$\delta \quad=$ Membrane thickness

The term $(\delta / k)$ in the middle present the thermal resistance where the conduction resistance of the fixed plate membrane and the other two terms present the convective thermal resistance.

For validation of the calculations, the effectiveness of the cross-flow heat exchanger is given by Navarro and Cabezas-Gómez (2007):

$$
\begin{aligned}
& \varepsilon=1-\exp \left\{H_{c}^{-1} \cdot N T U^{0.22}\left[\exp \left(-H_{c} \cdot N T U^{0.78}\right)-1\right]\right\} \\
& H_{c}=\frac{\left(\dot{m} c_{p}\right)_{\min }}{\left(\dot{m} c_{p}\right)_{\max }}
\end{aligned}
$$

where, $H_{c}$ is the heat capacity ratio.

\section{Results}

The dimensions of cross-flow heat exchanger employed in this study are shown in Table 1 and the air temperature and air velocity data are presented in Table 2. Calculations are carried out using data in Table 1 and 2 as a base. Pre-set temperature data are chosen to represent the temperature conditions of hothumid climate. With the characteristics of the heat exchanger given in Table 1, heat transfer is analysed for both the hot ( $x$ direction) and cold ( $y$ direction) streams based on the temperature data and air velocity in Table 2.

\section{Heat Transfer Analysis}

Using Equations 3 and 4, transferred heat $(Q)$ for hot and cold streams is calculated for air velocity ranges from 1.0 to $3.0 \mathrm{~m} / \mathrm{s}$, air temperature of hot intake stream $\left(T_{h i}\right)$ at $33^{\circ} \mathrm{C}$ and air temperatures of hot exhaust stream $\left(T_{h e}\right)$ ranges from 20 to $28^{\circ} \mathrm{C}$. The results are plotted in Fig. 2 . The variation of transferred heat and $T_{h e}$ is illustrated in Fig. 3 for air velocity ranges from 1.0 to $3.0 \mathrm{~m} / \mathrm{s}$.

\section{Effectiveness Analysis}

Using the model, the effectiveness $(\varepsilon)$ in terms of temperature and NTU-method are calculated for both hot and cold streams by applying Equations 9 and 10 for temperature effectiveness, and applying Equations 11 to 14 for NTU-effectiveness. The temperature and velocity data of the fluids (air) at hot (preset) and cold streams in Table 2 are used. Figure 4 illustrates the effectiveness of the heat exchanger in terms of temperature effectiveness and NTUeffectiveness based on the three different air velocities ranged from 1.0 to $3.0 \mathrm{~m} / \mathrm{s}$, air temperature of hot intake stream $\left(T_{h i}\right)$ at $33^{\circ} \mathrm{C}$ and air temperatures of hot exhaust stream $\left(T_{h e}\right)$ ranges from 20 to $28^{\circ} \mathrm{C}$. The effectiveness is based on the intake and exhaust temperature. 
Table 1. Characteristics of the heat exchanger studied

\begin{tabular}{llll}
\hline Name & Symbol & Value & Unit \\
\hline Cross section area & $A$ & 13.00 & $\mathrm{~m}^{2}$ \\
Length of channel in the $x$ direction & $l_{x}$ & 0.250 & $\mathrm{~m}$ \\
Length of channel the $y$ direction & $l_{y}$ & 0.250 & $\mathrm{~m}$ \\
Length of airstream of the plates & $l_{z}$ & 0.110 & $\mathrm{~m}$ \\
Sub-channel height & $d$ & 0.002 & $\mathrm{~m}$ \\
\hline
\end{tabular}

Table 2. Air temperature and air velocity data

\begin{tabular}{llll}
\hline Name & Symbol & Value (range) & Unit \\
\hline Temperature-hot intake & $T_{h i}$ & $31-33$ & ${ }^{\circ} \mathrm{C}$ \\
Temperature-hot exhaust & $T_{h e}$ & $20-28$ & ${ }^{\circ} \mathrm{C}$ \\
Temperature-cold intake & $T_{c i}$ & $16-24$ & ${ }^{\circ} \mathrm{C}$ \\
Temperature-cold exhaust & $T_{c e}$ & 25 & ${ }^{\circ} \mathrm{C}$ \\
Air velocity 1 & $V_{l}$ & 1.0 & $\mathrm{~m} / \mathrm{s}$ \\
Air velocity 2 & $V_{2}$ & 2.0 & $\mathrm{~m} / \mathrm{s}$ \\
Air velocity 3 & $V_{3}$ & 3.0 & $\mathrm{~m} / \mathrm{s}$ \\
\hline
\end{tabular}

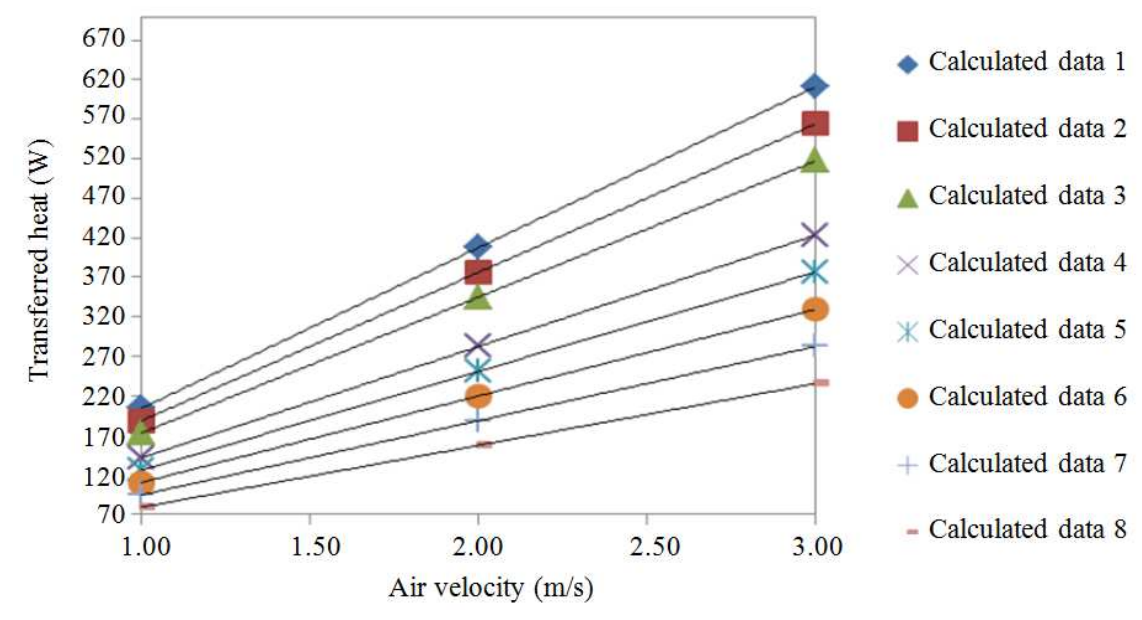

Fig. 2. Transferred heat versus air velocity

\section{Discussion}

In this study, the transferred heat is found to be in a range of 78.3 to $611.4 \mathrm{~W}$ with the lowest value corresponds to $1.0 \mathrm{~m} / \mathrm{s}$ and the highest value corresponds $3.0 \mathrm{~m} / \mathrm{s}$. Thus, it can be seen that the transferred heat increases as air velocity increases. From the calculated data, it is found that the increasing $T_{\text {he }}$ gives significant impact to the transferred heat. Maximum transferred heat of 407. $6 \mathrm{~W}$ is achieved at $20^{\circ} \mathrm{C}$ and minimum transferred heat of $156.7 \mathrm{~W}$ is calculated at $28^{\circ} \mathrm{C}$ for air velocity of $2.0 \mathrm{~m} / \mathrm{s}$. (Fig. 3). As can be seen, transferred heat decreases with increasing $T_{h e}$ as suggested by (Min et al., 2012).

Results in Fig. 4 show that effectiveness decreases as air velocity increases. From the figure, the temperature effectiveness is reasonably consistent with the NTUeffectiveness. As can be seen, the agreement of the results obtained is generally good within $2 \%$ difference between the temperature effectiveness and NTU-effectiveness. A detailed calculated data of temperature effectiveness against air velocity for eight different cases is shown in Fig. 5. For all cases, again it can be seen that the effectiveness decreases with increasing air velocity. The effectiveness ranged from 55.6 to $76.5 \%$ for air velocity of $1.0 \mathrm{~m} / \mathrm{s} ; 50$ to $75 \%$ for air velocity of 2.0 $\mathrm{m} / \mathrm{s}$ and 42.9 to $73.3 \%$ for air velocity of $3.0 \mathrm{~m} / \mathrm{s}$. The highest temperature effectiveness of $76.5 \%$ was achieved at $1.0 \mathrm{~m} / \mathrm{s}$ and the lowest temperature effectiveness of $42.9 \%$ was achieved at $3.0 \mathrm{~m} / \mathrm{s}$. When the air velocity is low, the residence time is high thus the amount of energy transferred would be less (Yau and Ahmadzadehtalatapeh, 2010). Therefore, air velocity gives significant impact to the effectiveness of heat exchanger. This is in agreement with the results obtained by several authors (Mardiana-Idayu and Riffat, 2011; Riffat and Gan, 1998). Using Equations 15 to 18 , the NTU-effectiveness of the heat exchanger versus NTU ( 0.8 to 2.6$)$ is calculated and illustrated in Fig. 6. For these air velocities, the NTU-effectiveness is found to be in a range of 0.5 to 0.7 with the highest value corresponds to 2.6 NTU number. From the figure, it can be seen that the NTU-effectiveness increases with increasing NTU (Navarro and Cabezas-Gómez, 2007). 


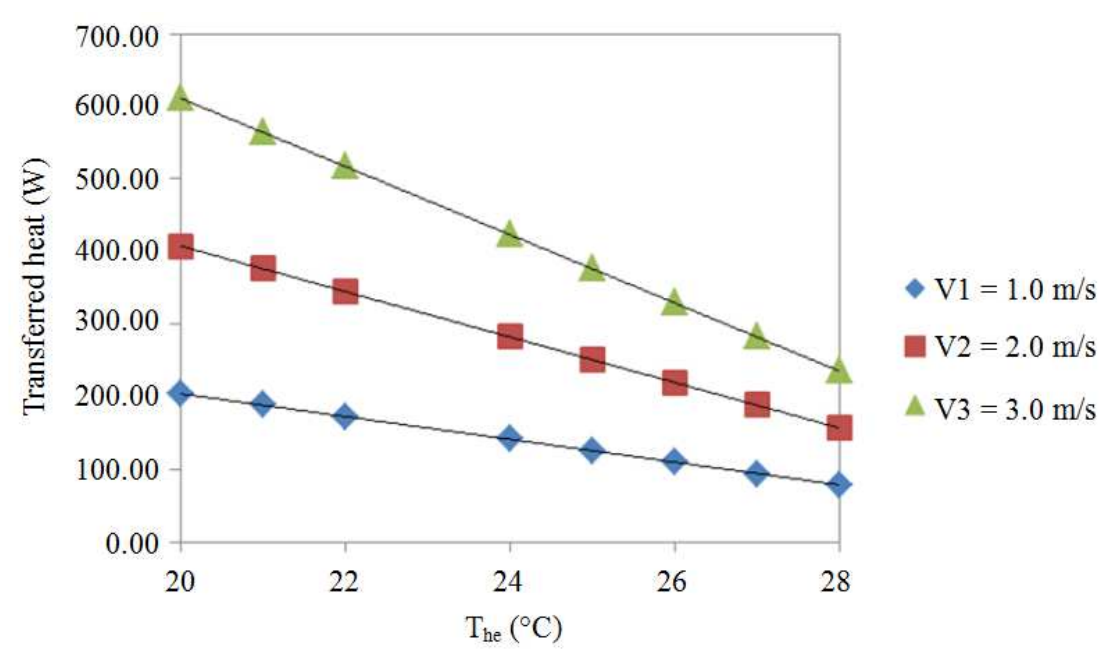

Fig. 3. Transferred heat versus air temperature of hot exhaust stream $\left(\mathrm{T}_{\text {he }}\right)$ for three different air velocities

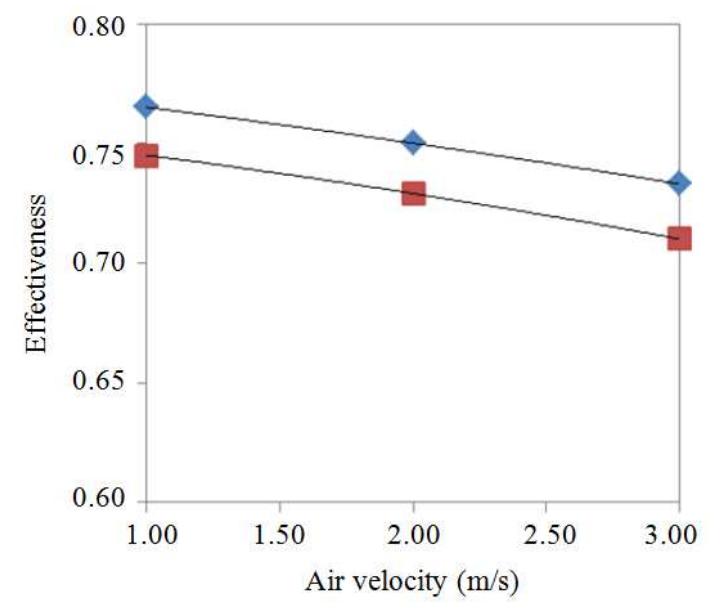

- $\varepsilon$ (Temperature effectiveness)

$\varepsilon$ (NTU-effectiveness)

Fig. 4. Effectiveness of the heat exchanger in terms of temperature effectiveness and NTU-effectiveness

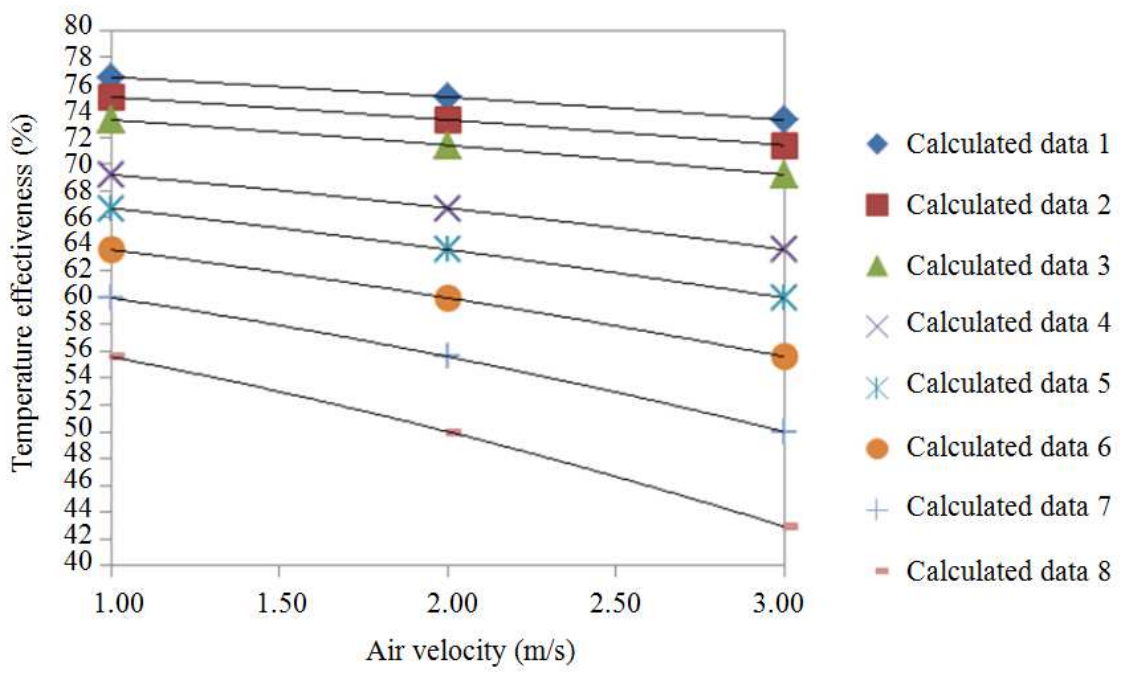

Fig. 5. Calculated data of temperature effectiveness versus air velocity for eight different cases 


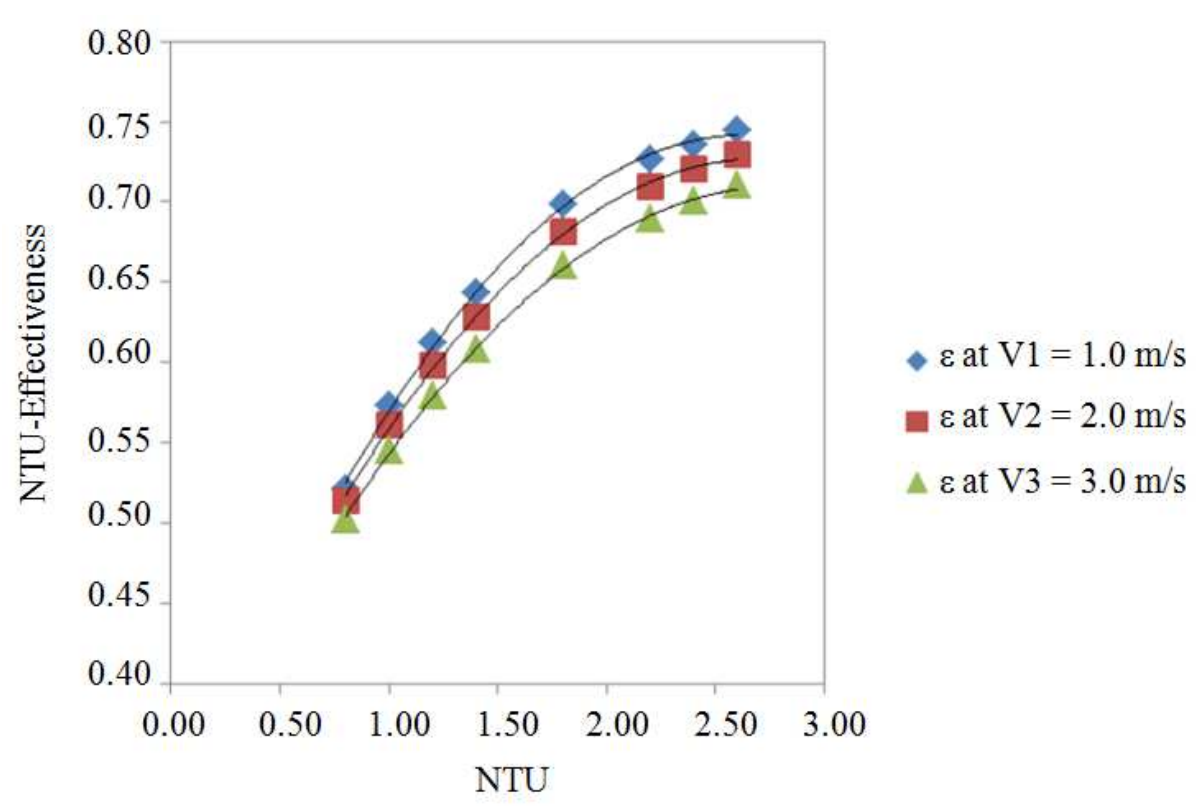

Fig. 6. NTU-effectiveness of the heat exchanger versus NTU number

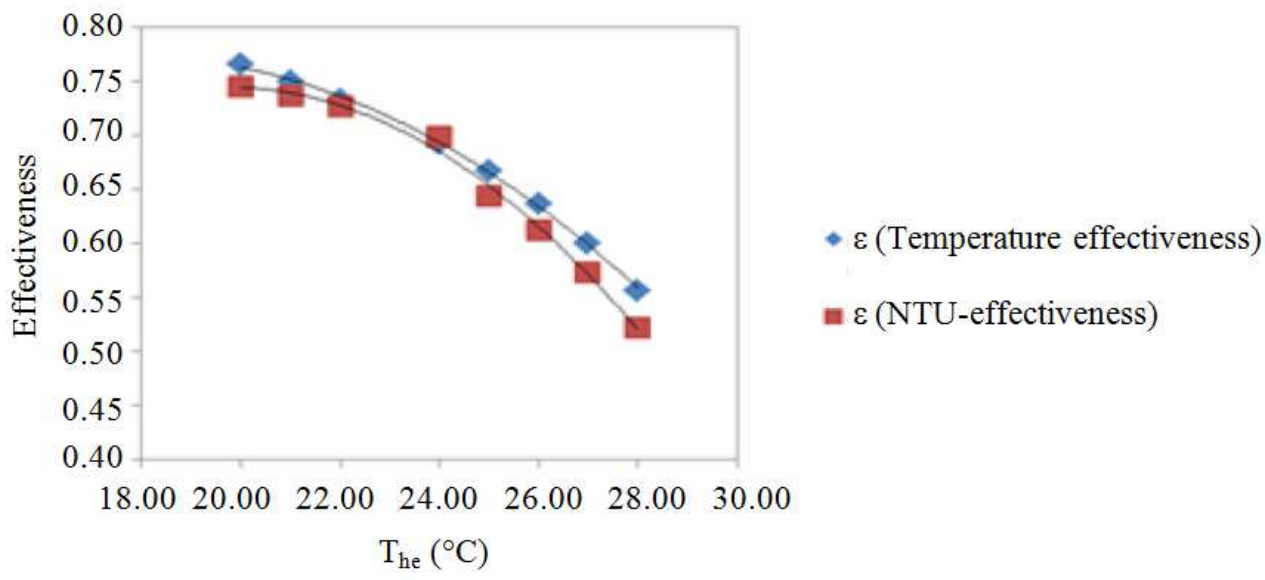

(a)

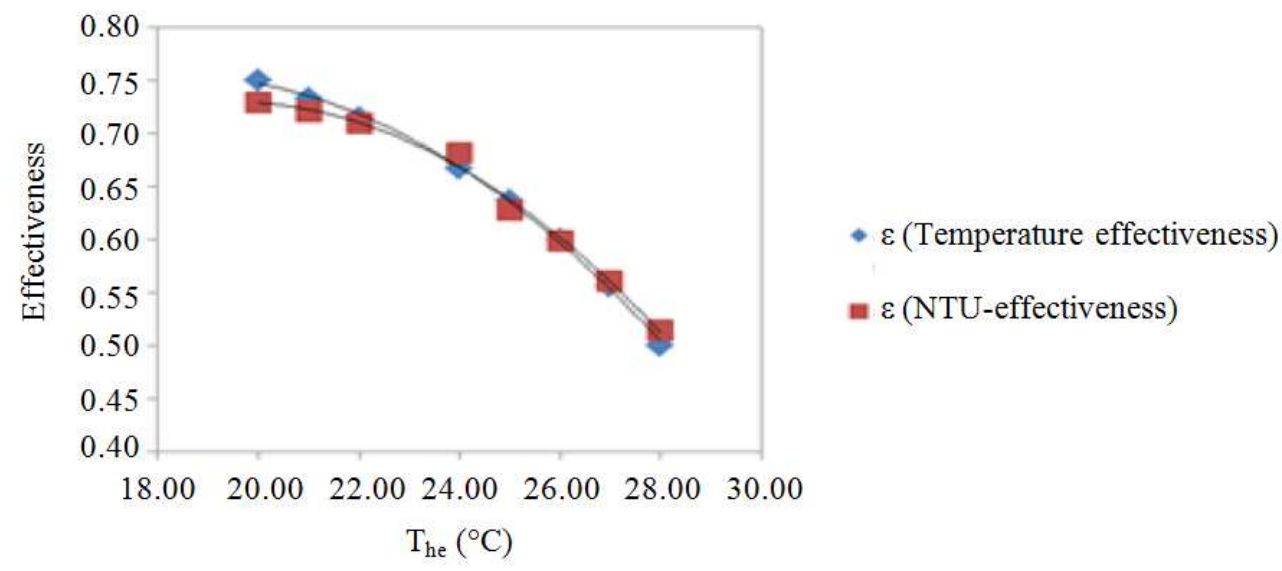

(b) 


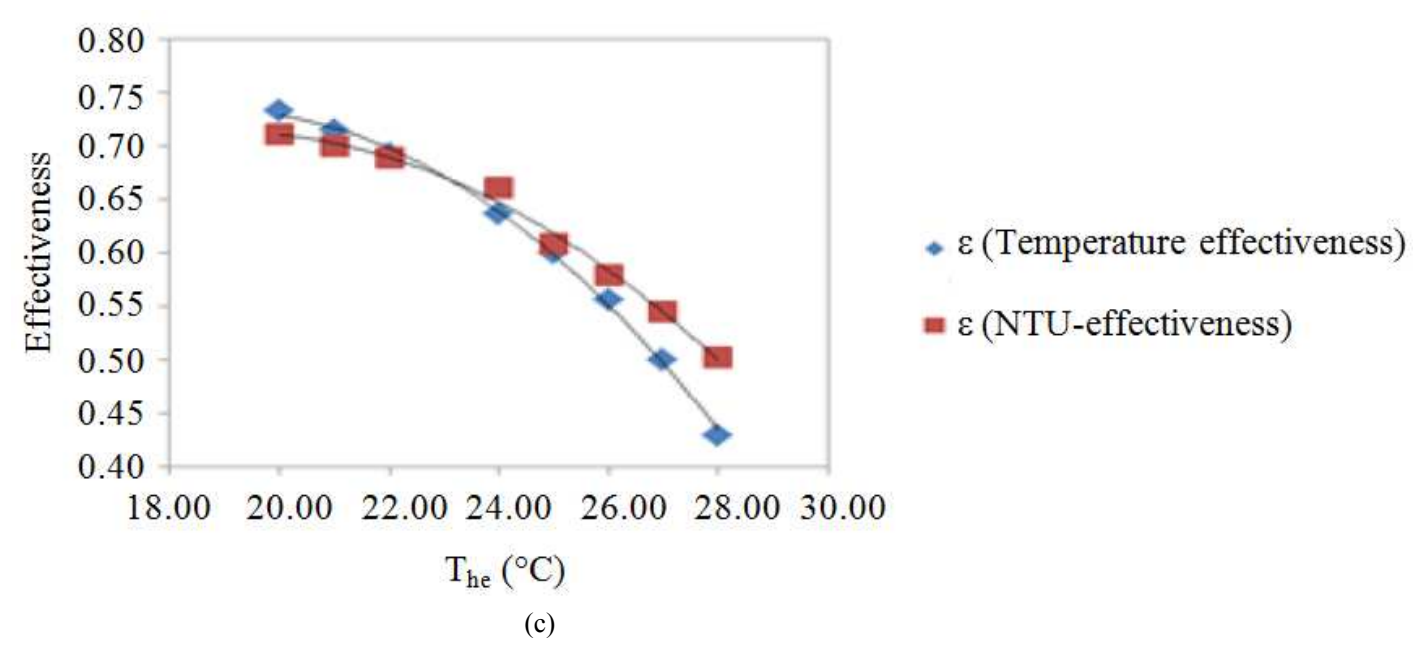

Fig. 7. Effectiveness of heat exchanger at air velocity of (a) $1.0 \mathrm{~m} / \mathrm{s}$ (b) $2.0 \mathrm{~m} / \mathrm{s}$ and (c) $3.0 \mathrm{~m} / \mathrm{s}$

The effectiveness of the heat exchanger versus air temperature of exhaust stream $\left(T_{h e}\right)$, calculated at three different air velocities $V_{l}=1.0 \mathrm{~m} / \mathrm{s}(\mathrm{a}), V_{2}=2.0 \mathrm{~m} / \mathrm{s}$ (b) and $\mathrm{V}_{3}=3.0 \mathrm{~m} / \mathrm{s}$ (c) is shown in Fig. 7 , with $T_{h i}$ at $33^{\circ} \mathrm{C}$ and temperature difference $(\Delta T)$ at $6^{\circ} \mathrm{C}$. From the figures, with $T_{h e}$ ranges from 20 to $28^{\circ} \mathrm{C}$, it can be seen that the effectiveness reduces with increasing air temperature of exhaust stream. In the three cases of air velocity, the highest value of effectiveness is calculated at $20^{\circ} \mathrm{C}$ and the lowest is calculated at $28^{\circ} \mathrm{C}$.

\section{Conclusion}

This paper presents a detailed heat and effectiveness analysis for a cross-flow heat exchanger for potential energy recovery application in hot-humid climate. It is found that for the present cross-flow arrangement, as the air velocity increases, the effectiveness decreases and transferred heat increases. Besides, the effectiveness and transferred heat values reduce with increasing air temperature of exhaust stream. The calculated temperature effectiveness is in good agreement with the results obtained using NTU-effectiveness method.

\section{Funding Information}

This research is supported by ERGS Ministry of Education Malaysia 203/PTEKIND/6730116 and RUI Universiti Sains Malaysia Grant (1001/PTEKIND/811229).

\section{Author's Contributions}

All authors contributed equally to this work. All authors discussed the results and implications and commented on the manuscript at all stages.
A.R.S. Masitah: Performed experiments, analysed data and wrote the paper.

Mardiana I Ahmad: Supervised the project, designed the physical model and experiments and wrote the paper.

Y.M. Yatim: Supervised the project, performed the theoretical analyses and wrote the paper.

\section{Ethics}

We maintained highest possible ethical standards integrity regarding data gathering and analysis.

\section{References}

Alonso, M.J., P. Liu, H.M. Mathisen, G. Ge and C. Simonson, 2014. Review of heat/energy recovery exchangers for use in ZEBs in cold climate countries. Build. Environ., 84: 228-237.

DOI: 10.1016/j.buildenv.2014.11.014

Hviid, C.A. and S. Svendsen, 2011. Analytical and experimental analysis of a low-pressure heat exchanger suitable for passive ventilation. Energy Build., 43: 275-284. DOI: $10.1016 /$ j.enbuild.2010.08.003

Kragh, J., J. Rose, T.R. Nielsen and S. Svendsen, 2007. New counter flow heat exchanger designed for ventilation systems in cold climates. Energy Build., 39: 1151-1158. DOI: 10.1016/j.enbuild.2006.12.008

Lin, S., J. Broadbent and R. McGlen, 2005. Numerical study of heat pipe application in heat recovery systems. Applied Thermal Eng., 25: 127-133. DOI: 10.1016/j.applthermaleng.2004.02.012

Mardiana-Idayu, A. and S.B. Riffat, 2011. An experimental study on the performance of enthalpy recovery system for building applications. Energy Build., 43: 2533-2538.

DOI: $10.1016 /$ j.enbuild.2011.06.009 
Mardiana-Idayu, A. and S.B. Riffat, 2012. Review on heat recovery technologies for building applications. Renewable Sustainable Energy Rev., 16: 1241-1255. DOI: 10.1016/j.rser.2011.09.026

Mardiana-Idayu, A. and S.B. Riffat, 2013. Review on physical and performance parameters on heat recovery technologies for building applications. Renewable Sustainable Energy Rev.

Min, J.C.,Su, M. and Wang, L.N., 2012. Experimental and theoretical investigation of membrane-based energy recovery ventilator performance. International J. Air-Conditioning Refrigeration., 20: 1-9. DOI: $10.1112 / \mathrm{S} 2010132511500040$

Min, J. and M. Su, 2010. Performance analysis of a membrane-based energy recovery ventilator: Effects of membrane spacing and thickness on the ventilator performance. Applied Thermal Eng., 30: 991-997. DOI: 10.1016/j.applthermaleng.2010.01.010

Nasif, M., R. AL-Waked, G. Morrison and M. Behnia, 2010. Membrane heat exchanger in HVAC energy recovery systems, systems energy analysis. Energy Build., 40: 1833-1840.

DOI: $10.1016 /$ j.enbuild.2010.05.020

Navarro, H.A. and L.C. Cabezas-Gómez, 2007. Effectiveness-NTU computation with a mathematical model for cross-flow heat exchangers. Brazilian J. Chem. Eng. DOI: /10.1590/S0104-66322007000400005

Persily, A., 1982. Evaluation of an air-to-air heat exchanger. Environ. Int., 8: 453-459. DOI: 10.1016/0160-4120(82)90063-0

Pongsoi, P., S. Pikulkajorn and S. Wong, 2012. Effect of fin pitches on the optimum heat transfer performance of crimped spiral fin-and-tube heat exchangers. Int. J. Heat Mass Trans., 55: 6655-6566.

DOI: 10.1016/j.ijheatmasstransfer.2012.06.061

Riffat, S.B. and G. Gan, 1998. Determination of effectiveness of heat-pipe heat recovery for naturally-ventilated buildings. Applied Thermal Eng., 18: 121-130.

DOI: $10.1016 / \mathrm{S} 1359-4311(97) 00033-1$

Sauer, H.J. and R.H. Howell, 1981. Promise and potential of air-to-air energy recovery systems. Int. J. Refrigerat, 4: 182-194. DOI: 10.1016/0140-7007(81)90049-9

Shah, R.K. and D.P. Sekulic, 2003. Fundamentals of heat exchanger design. 1st Edn., John Wiley and Sons, New York, ISBN-10: 0471321710. pp: 941.

Shurcliff, W., 1988. Air-to-air heat exchangers for houses. Ann. Rev. Energy.

Soylemez, M.S., 2000. On the optimum heat exchanger sizing for heat recovery. Energy Convers. Manage., 41: $1419-1427$.

DOI: $10.1016 / \mathrm{S} 0196-8904(99) 00181-8$
Xie, G., Q. Wang and B. Sunden, 2009. Parametric study and multiple correlations on air-side heat transfer and friction characteristics of fin-and-tube heat exchangers with large number of large-diameter tube rows. Applied Thermal Eng., 29: 1-16. DOI: 10.1016/j.applthermaleng.2008.01.014

Yau, Y.H. and M. Ahmadzadehtalatapeh, 2010. A review on the application of horizontal heat pipe heat exchangers in air conditioning systems in the tropics. Applied Thermal Eng., 30: 77-84. DOI: 10.1016/j.applthermaleng.2009.07.011

Yau, Y.H., 2001. Theoretical determination of effectiveness for heat pipe heat exchangers operating in naturally ventilated tropical buildings. J. Power Energy, 215: 389-397. DOI: $10.1243 / 0957650011538604$

Zhang, L.Z. and Y. Jiang, 1999. Heat and mass transfer in a membrane-based energy recovery ventilator. J. Membrane Sci., 163: 29-38.

DOI: $10.1016 / \mathrm{S} 0376-7388(99) 00150-7$

\section{Nomenclature}

A Surface area, $\mathrm{m}^{2}$

$c_{p} \quad$ Specific heat, $\mathrm{J} / \mathrm{kg} .{ }^{\circ} \mathrm{C}$

$h \quad$ Convective heat transfer coefficient, $\mathrm{W} / \mathrm{m}^{2} .{ }^{\circ} \mathrm{C}$

$d \quad$ Channel height, $\mathrm{m}$

$k \quad$ Thermal conductivity, $\mathrm{W} / \mathrm{m} .{ }^{\circ} \mathrm{C}$

$m \quad$ Mass airflow rate, $\mathrm{kg} / \mathrm{s}$

$n \quad$ Number of channel

$\mathrm{Nu} \quad$ Nusselt number

Re Reynolds number

$\mathrm{Pr} \quad$ Prandlt number

$u \quad$ Air velocity in the channel, $\mathrm{m} / \mathrm{s}$

$Q \quad$ Heat transfer rate, $\mathrm{W}$

$T \quad$ Temperature, ${ }^{\circ} \mathrm{C}$

$x, y, z \quad$ Coordinates, $\mathrm{m}$

$l_{x}, l_{y}, l_{z} \quad$ Channel length, $\mathrm{m}$

$v \quad$ Kinematics viscosity, $\mathrm{m}^{2} / \mathrm{s}$

$\alpha \quad$ Thermal diffusivity, $\mathrm{m}^{2} / \mathrm{s}$

NTU Number of Transfer Unit

$U \quad$ Overall heat transfer, $\mathrm{W} / \mathrm{m}^{2} .{ }^{\circ} \mathrm{C}$

$H_{c} \quad$ Heat capacity ratio

$\delta \quad$ Membrane thickness, $\mathrm{m}$

$\varepsilon \quad$ Effectiveness

\section{Subscripts}

$\begin{array}{ll}a & \text { Air } \\ s & \text { Surface } \\ i & \text { Intake } \\ e & \text { Exhaust } \\ h & \text { Hot stream } \\ c & \text { Cold stream } \\ \max & \text { Maximum } \\ \min & \text { Minimum }\end{array}$

